\title{
Drug utilization study of anti-hypertensive drugs in a tertiary care hospital
}

\author{
D. Bhavika *, V. Prasanna, B. Swathi
}

Department of Pharmacology, Osmania Medical College, Hyderabad, Telangana, India

Received: 03 June 2016

Accepted: 04 July 2016

*Correspondence to:

Dr. Bhavika Domalapally, Email: bhavika_mb6@ yahoo.co.in

Copyright: (C) the author(s), publisher and licensee Medip Academy. This is an openaccess article distributed under the terms of the Creative Commons Attribution NonCommercial License, which permits unrestricted noncommercial use, distribution, and reproduction in any medium, provided the original work is properly cited.

\begin{abstract}
Background: Hypertension is a major non-communicable disease and a risk factor for cardiovascular diseases. The antihypertensive drugs used for its management constitute a significant portion of the medicines prescribed in a health care centre. The aim of our study was to analyse the utilization pattern of anti-hypertensive drugs at a tertiary care hospital in accordance with the WHO prescription indicators.

Methods: A prospective cross sectional observational study was carried out in the outpatient of general medicine department of Osmania General Hospital. The prescriptions of the hypertensive patients visiting the outpatient were monitored. From the data collected, the prescription pattern of antihypertensive drugs, and WHO prescription indicators, were analysed.

Results: Out of the 301study subjects, $134(44.51 \%)$ were males and 167 $(55.48 \%)$ were females, with the maximum number of patients (197) falling in the age group 51-70 years. Among the antihypertensive drugs prescribed, Amlodipine was most frequently prescribed $(53.15 \%)$. The frequently used drugs for monotherapy - amlodipine (26.91\%) and for two drug therapy amlodipine+enalapril (17.27\%), and for three drug therapy atenolol+enalapril+nifedipine $(2.32 \%)$. The WHO prescribing indicators as analyzed from the data collected are; Average number of drugs prescribed per encounter - 5.64/prescription, Percentage of medicines prescribed by generic name $-89.22 \%$, Percentage of medicines prescribed from essential drug list $90.17 \%$.

Conclusions: The study provides an insight into antihypertensive drug usage pattern in tertiary care hospital and their rational use. The study emphasizes the need for preventive measures and effective educative measures in the population about hypertension.
\end{abstract}

Keywords: Drug utilization study, Hypertension, Antihypertensive drugs

\section{INTRODUCTION}

Hypertension is the leading non communicable disease risk attributing to morbidity and mortality. In India, hypertension is a significant non communicable disease risk attributing to $10 \%$ of all deaths. Hypertension attributes to $10 \%$ of ischemic heart disease, $21 \%$ of peripheral vascular disease, $24 \%$ of Acute MI, and $29 \%$ of Strokes. ${ }^{1}$ The overall prevalence for hypertension in India was estimated to be $29.8 \%$ according to a study by Anchala $\mathrm{R}$ et al. $^{2}$ Appropriate management of hypertension can bring down the incidence of these conditions. With the increasing prevalence of hypertension, there is an increase in the use of antihypertensive drugs, which to a far extent can improve the quality of life and decrease the attributed morbidity and mortality. Thus, appropriate use of antihypertensive drugs in a society, in an efficient manner is an utmost requirement. Further there is also a requirement for educating the people about hypertension and the consequences of its inadequate management, and also for implementing strategies for prevention as well.

Drug utilization research was defined by WHO in 1977 as "the marketing, distribution, prescription and use of drugs in a society, with special emphasis on the resulting medical, social, and economic consequences". ${ }^{3}$ 
Drug utilization research provides an insight into the drug use pattern (extent of drug use and trends in drug use) and rational use of a drug (prescription of a welldocumented drug at an optimal dose, together with the correct information, at an affordable price). The outcomes of this contribute to our knowledge about drug effectiveness and safety. It also provides information about cost effectiveness of the drugs. The study can be used to evaluate the extent of drug use in a particular region, and even to evaluate the extent to which drugs are overused or underused. It can also help in comparison of the trend in drug use with the standard guidelines. ${ }^{3}$ The information on patterns of drug utilization can be useful for designing a drug policy and reviewing the health care budget. Drug utilization study can be used to evaluate the pattern of use of a particular group of drugs according to age, sex, morbidity at various levels of health care system which may contribute to make amendments in the drug policy of a health care system.

The anatomical, therapeutic, chemical (ATC) classification system serves as an international standard for classifying drugs. ${ }^{4}$ Defined daily dose (DDD) is an important unit of measurement in drug utilization studies. DDD is the assumed average maintenance dose per day for a drug used for its main indication in adults. ${ }^{5}$ The main purpose of using ATC/DDD system is to compare data between countries.

Our study aims at evaluating the current trends in prescription of antihypertensive drugs in Osmania General Hospital, Hyderabad, Telangana, a tertiary care hospital. Antihypertensive drugs being one of the major groups of drugs prescribed in the hospital, this study will give an idea about the present trend in antihypertensive drugs prescription, as well as the extent of use. This will also provide a measure of burden of hypertension and its associated co-morbidities on the society. Simultaneously, the adverse drug reactions encountered with antihypertensive drugs will be monitored, which contributes to pharmacovigilance.

\section{METHODS}

\section{Study design}

A prospective cross sectional observational study was carried out in the outpatient of department of general medicine of Osmania General Hospital, a tertiary care teaching hospital, in Hyderabad. The study was started after approval from the institutional ethics committee and the hospital authorities.

\section{Selection criteria of patients}

The study population included all patients diagnosed as hypertensive and aged 18 years and above, visiting the medicine outpatient. Patients who were not willing to participate were not included in the study.

\section{Data collection and analysis}

Data was collected over a period of three months in accordance with a predesigned proforma prepared to meet the requirements of the study. The data collected included socio-demographic details like age, sex, educational status, clinical details such as medical history, diagnosis and other co-morbidities, the drugs prescribed (antihypertensive drugs and other drugs in the prescription). Adverse drug reactions noticed during the study were also noted down. The data was collected and WHO core drug prescribing indicators were analysed.

The data collected was represented using the ATC/DDD system. The drug usage is calculated using the following formula.

$$
\begin{aligned}
& \text { Drug usage }[\mathrm{DDD}] * \\
& =\frac{\text { Number of items used } \times \text { Amount of drug per item }(\mathrm{mg})}{\text { WHO recommended DDD of a drug }}
\end{aligned}
$$

* DDD is defined daily dose.

\section{RESULTS}

A total of 301 patients were included in the study and their prescriptions were analysed. Among them, 134 $(44.51 \%)$ were males and $167(55.48 \%)$ were females. Table 1 show the age and sex distribution of the patients. Maximum numbers of patient were in the age group of 51-70 years, which is $192(63.78 \%)$. All the patients were uneducated.

Table 1: Age and sex distribution of the patients.

\begin{tabular}{|llll|}
\hline $\begin{array}{l}\text { Age } \\
\text { group }\end{array}$ & $\begin{array}{l}\text { Male 134 } \\
(\mathbf{4 4 . 5 1 \% )}\end{array}$ & $\begin{array}{l}\text { Female } \\
\mathbf{1 6 7}(\mathbf{5 5 . 4 8 \%})\end{array}$ & Total 301 \\
\hline $18-25$ & - & - & - \\
\hline $26-50$ & $33(24.62 \%)$ & $60(35.92 \%)$ & $93(30.89 \%)$ \\
\hline $51-70$ & $93(69.4 \%)$ & $99(59.28 \%)$ & $192(63.78 \%)$ \\
\hline$>70$ & $8(5.97 \%)$ & $8(4.79 \%)$ & $16(5.31 \%)$ \\
\hline
\end{tabular}

\section{Prescription pattern of antihypertensive drugs}

All the antihypertensive drugs prescribed and their frequency is presented in Table 2. Among the antihypertensive drugs prescribed amlodipine was the most commonly prescribed drug with a frequency of 160 $(53.15 \%)$, followed by enalapril with a frequency of 154 $(51.16 \%)$. The least commonly prescribed antihypertensive was telmisartan with a frequency of 11 (3.65\%). The utilization pattern of different antihypertensive drugs is shown in Table 3. The number of patients who were on monotherapy, two drug therapy and three drug therapy for treatment of hypertension are shown in the Table 4. 


\section{Co-morbidities in study population}

The co-morbidities observed in the patients and their frequency was noted. $93(30.89 \%)$ of patients were diagnosed as having type II diabetes along with hypertension, which is followed by patients with a history of stroke, which counts to $64(21.26 \%) .66(21.92 \%)$ patients were diagnosed as hypertensive with no other comorbidities.

Table 2: List of antihypertensive drugs prescribed.

\begin{tabular}{|c|c|c|c|c|c|}
\hline Drug & No. of encounters & Percentage of encounters $\%$ & WHO DDD & ATC code & DDDs \\
\hline \multicolumn{6}{|c|}{ Calcium channel blockers (CCBs) } \\
\hline Amlodipine & 160 & 53.15 & $5 \mathrm{mg}$ & C08CA01 & 193.5 \\
\hline Nifedipine & 17 & 5.64 & $30 \mathrm{mg}$ & C08CA05 & 16.66 \\
\hline \multicolumn{6}{|c|}{ Beta blockers } \\
\hline Atenolol & 64 & 21.26 & $75 \mathrm{mg}$ & $\mathrm{C} 07 \mathrm{AB} 03$ & 42.66 \\
\hline Metoprolol & 14 & 4.65 & $150 \mathrm{mg}$ & $\mathrm{C} 07 \mathrm{AB} 02$ & 3.5 \\
\hline \multicolumn{6}{|c|}{ ACE inhibitors (ACEIs) } \\
\hline Enalapril & 154 & 51.16 & $10 \mathrm{mg}$ & C09AA02 & 110 \\
\hline \multicolumn{6}{|c|}{ Angiotensin receptor blockers (ARBs) } \\
\hline Telmisartan & 11 & 3.65 & $40 \mathrm{mg}$ & C09CA07 & 11 \\
\hline
\end{tabular}

Table 3: Utilization pattern of different antihypertensive drugs.

\begin{tabular}{|lll|}
\hline No. of drug & Pattern of use in hypertensive patients $(\mathbf{n = 3 0 1})$ & Pattern of use in patients with diabetes $(\mathbf{n = 9 3})$ \\
\hline Single drug & & $21(22.58 \%)$ \\
\hline Amlodipine & $81(26.91 \%)$ & $11(11.82 \%)$ \\
Atenolol & $21(6.97 \%)$ & $31(33.33 \%)$ \\
Enalapril & $73(24.25 \%)$ & - \\
Metoprolol & $5(1.66 \%)$ & - \\
Nifedipine & $6(1.99 \%)$ & $3(3.22 \%)$ \\
Telmisartan & $7(2.32 \%)$ & \\
\hline Two drugs & & $15(16.12 \%)$ \\
\hline Amlodepine+enalapril & $52(17.27 \%)$ & $3(3.22 \%)$ \\
Amlodepine+atenolol & $18(5.98 \%)$ & $4(4.3 \%)$ \\
Enalapril +atenolol & $11(3.65 \%)$ & $3(3.22 \%)$ \\
Enalapril+metoprolol & $5(1.66 \%)$ & $1(1.07 \%)$ \\
Others & $10(3.32 \%)$ & - \\
\hline Three drugs & & $1(1.07 \%)$ \\
\hline Atenolol+enalapril+nifedipine & $7(2.32 \%)$ & - \\
Enalapril+amlodipine+atenolol & $4(1.32 \%)$ & \\
Others & $1(0.33 \%)$ & \\
\hline
\end{tabular}

Table 4: Prescribing pattern of antihypertensive drugs in study subjects.

\begin{tabular}{|llll|}
\hline & $\begin{array}{l}\text { Number of } \\
\text { patients }\end{array}$ & Percentage of patients \% & Most commonly used drugs \\
\hline Mono-therapy & 193 & 64.11 & Amlodipine (26.91\% of patients) \\
\hline Two drug therapy & 96 & 31.89 & Amlodipine +enalapril (17.27\% of patients) \\
\hline Three drug therapy & 12 & 3.98 & Atenolol+enalapril+nifedipine (2.32\% of patients) \\
\hline
\end{tabular}

\section{Other non-antihypertensive drugs prescribed}

Table 6 shows the other drugs (non-antihypertensive drugs) in the prescriptions analysed. These drugs include anti diabetic drugs like metformin, glibenclamide, glimiperide, insulin, and analgesics (non-steroidal antiinflammatory drugs) like diclofenac, and antiplatelet agents like aspirin, clopidogrel, diuretics like furosemide, multivitamins, pantoprazole, ranitidine and others.

\section{Adverse drug reactions}

Among the prescriptions analysed 3 patients were noted to have experienced an adverse drug reaction. The ADR noted was cough, which was noted in patients receiving enalapril for hypertension. Cough was relieved on discontinuing enalapril. 


\section{WHO core prescribing indicators}

The WHO prescribing indicators as analysed from the data collected are;

- Average number of drugs prescribed per encounter 5.64/prescription

- Percentage of medicines prescribed by generic name $-89.22 \%$

- Percentage of medicines prescribed from essential drug list $-90.17 \%$

- Percentage of encounters with injection prescribed $3.98 \%$

- $\quad$ Percentage of drugs actually dispensed - $89.52 \%$.
The number of diabetic patients in the study -93 .

Table 5: Prescription pattern of antihypertensive drugs in diabetic patients.

\begin{tabular}{|ll|}
\hline \multicolumn{1}{|c|}{} & $\begin{array}{l}\text { Most commonly used antihypertensive } \\
\text { drugs in diabetic patients }\end{array}$ \\
\hline Monotherapy & $\begin{array}{l}\text { Enalapril } \\
\text { (33.33\% of diabetic patients) }\end{array}$ \\
\hline $\begin{array}{l}\text { Two drug } \\
\text { therapy }\end{array}$ & $\begin{array}{l}\text { Enalapril+amlodipine } \\
\text { (16.12\% of diabetic patients) }\end{array}$ \\
\hline $\begin{array}{l}\text { Three drug } \\
\text { therapy }\end{array}$ & $\begin{array}{l}\text { Enalapril+amlodipine+atenolol } \\
\text { (1.07\% of diabetic patients) }\end{array}$ \\
\hline
\end{tabular}

Table 6: List of other drugs prescribed.

\begin{tabular}{|c|c|c|c|c|c|c|}
\hline Drug & No. of encounters & $\%$ of encounters & $\begin{array}{l}\text { No. of units/items } \\
\text { issued }\end{array}$ & ATC Code & $\begin{array}{l}\text { WHO } \\
\text { DDD }\end{array}$ & DDDs \\
\hline Aspirin & 103 & 34.21 & 186 & N02BA01 & $3 g$ & 4.65 \\
\hline Atorvastatin & 94 & 31.22 & 237 & C10AA05 & $20 \mathrm{mg}$ & 118.5 \\
\hline B-Complex & 192 & 63.78 & 192 & - & - & - \\
\hline Calcium lactate & 86 & 28.57 & 87 & A12AA05 & $2 \mathrm{~g}$ & 13.05 \\
\hline Carbimazole & 1 & 0.33 & 1 & H03BВ01 & $15 \mathrm{mg}$ & 0.66 \\
\hline Chlorpheniramine & 18 & 5.98 & 27 & R06AB04 & $12 \mathrm{mg}$ & \\
\hline Clopidogrel & 36 & 11.96 & 36 & B01AC04 & $75 \mathrm{mg}$ & 36 \\
\hline Deriphyllin & 26 & 8.63 & 71 & R03DA55 & - & - \\
\hline Diclofenac & 63 & 20.93 & 120 & M01AB05 & $0.1 \mathrm{~g}$ & 60 \\
\hline Digoxin & 11 & 3.65 & 11 & C01AA05 & $0.25 \mathrm{mg}$ & 11 \\
\hline Frusemide & 35 & 11.62 & 52 & $\mathrm{C} 03 \mathrm{Ca} 01$ & $40 \mathrm{mg}$ & 51.5 \\
\hline Glibenclamide & 25 & 8.30 & 28 & A10BB01 & $7 \mathrm{mg}$ & 20 \\
\hline Glimiperide & 7 & 2.32 & 16 & A10BB12 & $2 \mathrm{mg}$ & 8 \\
\hline Insulin mixtard & 12 & 3.98 & $329 \mathrm{U}$ & A10AD30 & $40 \mathrm{U}$ & 8.22 \\
\hline Iron folic acid & 19 & 6.31 & 20 & B03BB51 & - & - \\
\hline Metformin & 84 & 27.9 & 200 & A10BA02 & $2 \mathrm{~g}$ & 50 \\
\hline Pantoprazole & 107 & 35.54 & 128 & $\mathrm{~A} 02 \mathrm{BC} 02$ & $40 \mathrm{mg}$ & 128 \\
\hline Paracetamol & 37 & 12.29 & 88 & N02BE01 & $3 \mathrm{~g}$ & 14.6 \\
\hline Phenytoin & 12 & 3.98 & 36 & N03AB02 & $0.3 \mathrm{~g}$ & 12 \\
\hline Ranitidine & 99 & 32.89 & 193 & A02BA02 & $0.3 \mathrm{~g}$ & 96.5 \\
\hline Thyroxine & 5 & 1.66 & 6 & H03AA01 & $0.15 \mathrm{mg}$ & 2 \\
\hline
\end{tabular}

\section{DISCUSSION}

Our present study is a drug utilization study of antihypertensive drugs, which constitute a major group of drugs prescribed, due to increasing prevalence of hypertension. Our study included 301 patients, including 134 (44.51) males and 167 (55.48) females (Table 1). The maximum number of patients, were from the age group of $51-70$ years. $192(63.78 \%)$ of patients are from this age group, and showing a slight predominance of male population (69.4\% of male population), whereas only $59.28 \%$ of female population are in this age group. A predominance of female population $(35.92 \%)$ over male population $(24.62 \%)$ was observed in the age group of 2650 years (Table 1$)$.
In this study, the WHO core prescription indicators were analysed. The average number of drugs prescribed per encounter was 5.64 drugs per prescription; this is because of the drugs prescribed for the treatment of other comorbidities. Percentage of medicines prescribed by generic name was $89.22 \%$ and $90.17 \%$ of medicines were prescribed from essential drug list. Percentage of encounters with injection prescribed was $3.98 \%$ the injections prescribed here refer to injection insulin mixtard prescribed for the treatment of diabetes mellitus. $89.52 \%$ of the drugs prescribed were actually dispensed at the hospital pharmacy.

The antihypertensive drugs prescribed were, amlodipine and nifedipine (calcium channel blockers), enalapril (ACE inhibitors), atenolol and metoprolol (beta blockers), 
telmisartan (angiotensin receptor blockers) (Table 2). Among these drugs, the antihypertensive drugs with maximum frequency of use was Amlodipine $(53.15 \%$ of encounters), followed by Enalapril which accounts for $51.16 \%$ of encounters, the next frequently used antihypertensive was Atenolol (21.26\%). The least frequently used antihypertensive was telmisartan $(3.65 \%$ of encounters). In a study by Mohd $\mathrm{AH}$ et al the most commonly prescribed antihypertensive among elderly patients was Amlodipine. ${ }^{6}$ Similarly in a study by Kaur S et al. Angiotensin converting enzyme inhibitors (ACE Inhibitors) and calcium channel blockers (CCBs) were the most commonly prescribed antihypertensive drugs followed by beta-blockers. ${ }^{7}$ The same pattern is observed in a study conducted by Hong Cheng, wherein most of the patients were receiving calcium channel blockers. ${ }^{8}$

In our study maximum number of patients were on mono therapy $(64.11 \%)$, followed by $31.89 \%$ of patients on two drug therapy, and $3.98 \%$ of patients were on three drug therapy (Table 4) for treatment of hypertension. Amlodipine was the frequently used drug for monotherapy $(26.91 \%)$, and the most commonly used drugs in two drug therapy were amlodipine+enalapril accounting for $17.27 \%$, and $2.32 \%$ of patients were on three drug therapy with atenolol+enalapril+nifedipine. This is in concurrence to the results obtained in a study by Kaur $\mathrm{S}$ et al wherein the most common single therapy agents were CCBs, and ACEI and CCBs were the commonly used two drug therapies. ${ }^{7}$

In our study the most common co-morbidity was diabetes mellitus (30.89\% of patients), followed by cerebrovascular accidents $(21.26 \%)$, and $8.63 \%$ of patients had history of coronary artery disease. Hypertension being the risk factor contributing to the comorbidities like cerebrovascular accidents, coronary artery disease, is the cause behind the observed frequency.

In our study, where diabetes was the most common comorbidity, the prescription pattern of antihypertensive drugs in patients who are diabetic as well as hypertensive was observed as

- $33.33 \%$ of diabetic and hypertensive patients were on enalapril as monotherapy

- Enalapril+amlodipine (in $16.12 \%$ of patients) were the frequently used drugs for two drug therapy

- Enalapril+amlodipine+atenolol (in 1.07\%) were frequently used in three drug therapy, for treatment of hypertension(Table 5).

In a study by Dhanraj E et al in patients suffering with diabetes and hypertension, ACEI were more frequently utilized as individual drug therapy, which is similar to our study, but ACEI and ARBs were the most utilized for two drug therapy, and in three drug combination ACEI and ARBs and diuretics were maximum used. ${ }^{9}$ The antihypertensive drugs prescribed are in concordance with the Joint National committee (JNC) 8 guidelines. ${ }^{10}$
On analysis of the other non-antihypertensive drugs prescribed (Table 6), it was found that B-complex was most frequently prescribed $(63.78 \%)$, followed by pantoprazole $(35.54 \%)$, aspirin $(34.21 \%)$, and atorvastatin (31.22\%), calcium lactate $(28.57 \%)$, metformin $(27.9 \%)$. This pattern observed is due to the presence of comorbidities like cerebrovascular accidents (stroke) and diabetes.

\section{CONCLUSION}

Our study showed that the most common antihypertensive used was amlodipine (CCB), and this is in concordance with other studies. The most common combination used for two drug therapy in our study was amlodipine and enalapril (CCB and ACEI), and that for three drug therapy being atenolol, enalapril and nifedipine (beta blocker, ACEI, and CCB). Among the patients, there was prevalence of other co-morbidities, single as well as multiple co-morbidities. The most common co-morbidity being diabetes. Due to the presence of other comorbidities, majority of which are consequence of hypertension (like cerebrovascular accidents, coronary artery disease) and even other co-morbidities ( diabetes, hyperthyroidism, hypothyroidism, COPD, respiratory tract infections), the average number of drugs per prescription was 5.64. The most frequently prescribed antihypertensive drug enalapril in diabetic patients is also in concordance with other studies, and also the standard treatment guidelines. Majority of the drugs were prescribed as generic and most of them were from essential drug list. The injections prescribed in our study were injection insulin, prescribed for treatment of diabetes. Majority of the drugs prescribed were dispensed.

One aspect from our study which can be noticed is the prevalence of co-morbidities, which are direct consequences of hypertension. It was observed that most of the patients were diagnosed as hypertensive for the first time only when they were admitted with the comorbidities like stroke, coronary artery disease. Thus, there is requirement for, preventive measures, and effective educative measures in the population about hypertension, and the consequences of inappropriate control of hypertension. This may reduce the associated morbidity and mortality due to unawareness of hypertension, and also reduces the financial burden incurred by it on the society. The increasing burden of hypertension, cardiovascular diseases, and other noncommunicable diseases, must be addressed and effective control measures should be implemented.

\section{ACKNOWLEDGEMENTS}

Authors thankful to Dr. Manohar, Professor and Head of the Department, faculty and staff members of Department of Medicine and the faculty of Department of Pharmacology, Osmania Medical College, Hyderabad for their kind support and valuable suggestions without which this work would not have been possible. 
Funding: No funding sources

Conflict of interest: None declared

Ethical approval: The study was approved by the Institutional Ethics Committee

\section{REFERENCES}

1. Mohan S, Campbell N, Chockalingam A. Time to effectively address hypertension in India. Indian $\mathbf{J}$ Med Res. 2013;137(4):627-31.

2. Anchala R, Kannuri NK, Pant H, Khan H, Franco $\mathrm{OH}$, Di Angelantonio E, et al. Hypertension in India: a systematic review and meta-analysis of prevalence, awareness, and control of hypertension. J Hypertens. 2014;32(6): 1170-7.

3. WHO. What is drug utilization research and why it is needed? In: Introduction to Drug Utilization Research-World Health Organization; 2003:8-12. Available at http://apps.who.int/medicinedocs/pdf/s4876e/s4876e. pdf. Accessed on 14 May 2016.

4. WHO. Drug classification systems. In: Introduction to Drug Utilization Research-World Health Organization; 2003:33-37. Available at http://apps.who.int/medicinedocs/pdf/s4876e/s4876e. pdf. Accessed on 14 May 2016.

5. WHO. Drug utilization metrics and their application. In: Introduction to Drug Utilization Research-World
Health Organization; 2003:38-41. Available at http://apps.who.int/medicinedocs/pdf/s4876e/s4876e. pdf. Accessed on 16 May 2016.

6. Mohd AH, Mateti UV, Konuru V, Parmar MY, Kunduru BR. A study on prescribing patterns of antihypertensives in geriatric patients. Perspect Clin Res. 2012;3(4):139-42.

7. Kaur S, Gupta S, Kumar D, Lal M, Gilani Z. Prescribing pattern of antihypertensive drugs in a tertiary care hospital in Jammu- a descriptive study. JK-Practitioner. 2012;17(4):38-41.

8. Cheng $H$. Prescribing pattern of antihypertensive drugs in a general hospital in central China. International Journal of Clinical Pharmacy. 2011;33(2):215-20.

9. Dhanaraj E, Raval A, Yadav R, Bhansali A, Tiwari P. Prescription pattern of antihypertensive agents in T2DM patients visiting tertiary care centre in North India. International Journal of Hypertension. 2012. Available at http://www.hindawi.com/journals/ijhy/2012/520915/.

10. James PA, Oparil S, Carter BL, Cushman WC, Himmelfarb CD, Handler J, et al. Evidence-based guideline for the management of high blood pressure in adults. Report from the panel members appointed to the eighth joint national committee (JNC 8). JAMA. 2014;311(5):507-20.

Cite this article as: Bhavika D, Prasanna V, Swathi B. Drug utilization study of antihypertensive drugs in a tertiary care hospital. Int $\mathbf{J}$ Basic Clin Pharmacol 2016;5:1580-5. 